\title{
REHABILITACION DE UNA MANZANA PARA VIVIENDAS-AULAS
}

La manzana está situada en el extremo noroeste del pueblo, dentro de la primera fase de rehabilitación global, cerca de la iglesia y detrás de la manzana cuyas obras están actualmente terminadas y destinadas a albergue de alumnos y profesores.

Esta manzana está formada por cuatro viviendas adosadas de una y dos plantas más sobrado, con algunas construcciones anexas como tinadas, leñeras y corrales. Su fachada principal, con orientación sur, da a una calle que sigue la pendiente de la ladera y que le da acceso; la fachada posterior y lateral derecha limita con el campo, y la lateral izquierda con otra calle que conduce a la iglesia.
Se propone destinarla para usos universitarios de forma que se divide la manzana en dos partes con el objetivo de que formen dos unidades con funcionamiento autónomo.

Cada unidad de vivienđa-aula será utilizada por una Universidad para realizar prácticas con pequeños grupos de alumnos y con cierta independencia de la organización general del pueblo.

Para ello cada unidad dispondrá de dos zonas: una para el alojamiento de los alumnos (unos dieciocho) más profesores y otra como aula-taller-laboratorio.

\section{DOS CASAS DESTINADAS A VIVIENDA-AULA (ZONA NORTE)}

Francisco Eduardo Arroyo Garrido, Julio Blanco Arranz, Juan Manuel Cáceres Tomé, Gerardo Cantalejo Carrasco y Jesús Cañas Muñoz

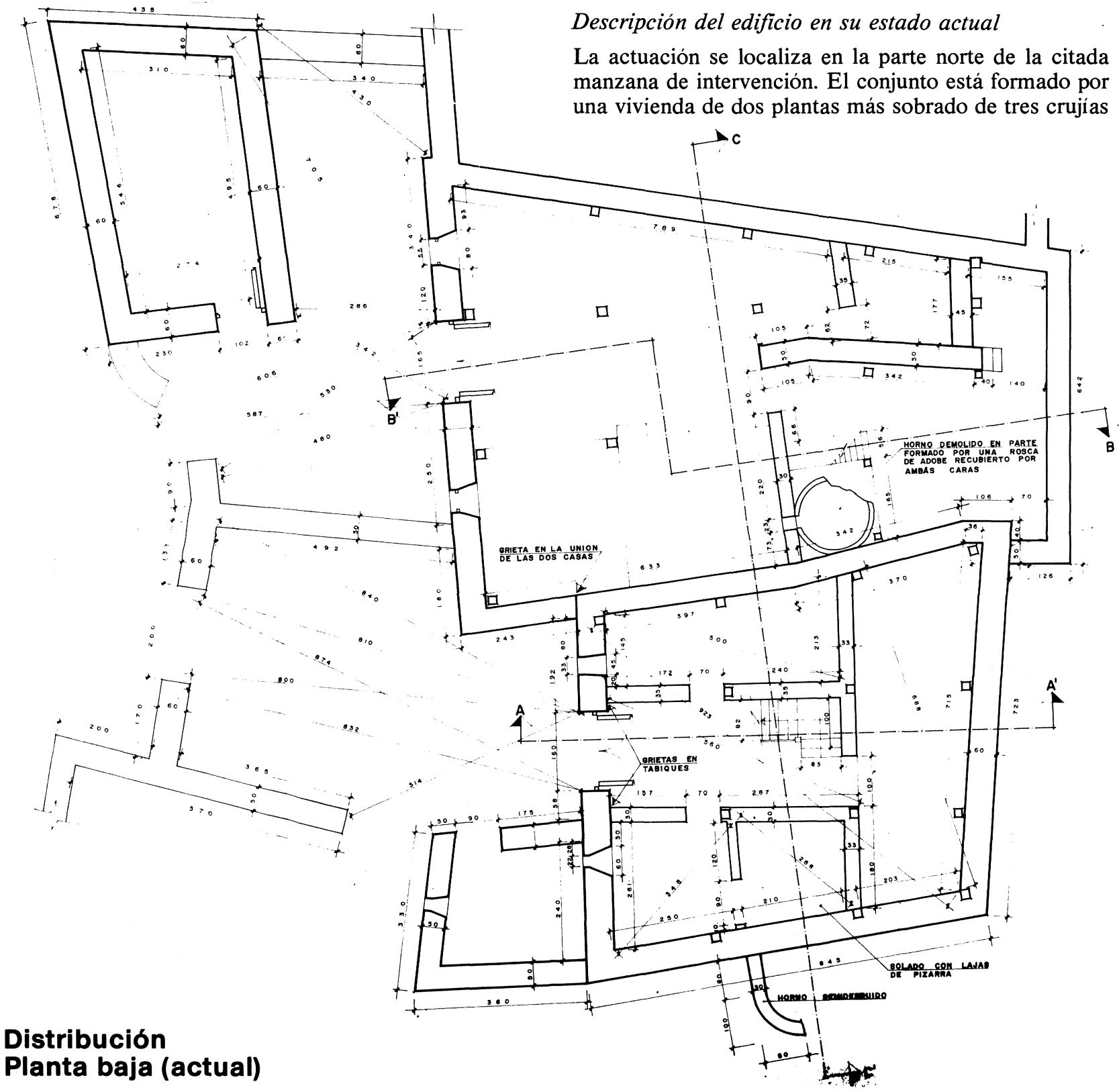



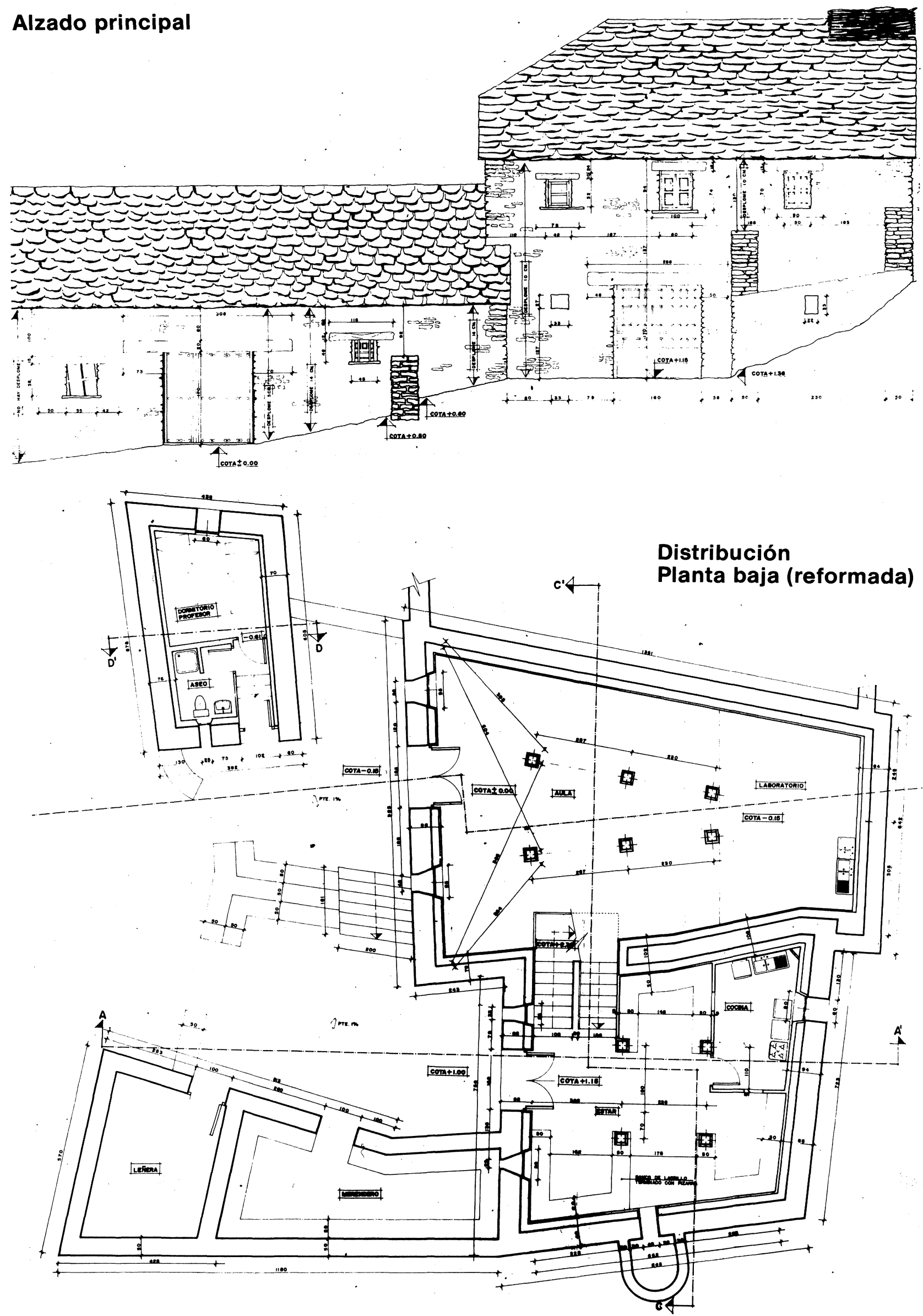
de ancho, una vivienda de una planta más sobrado también de tres crujías de ancho y adosada a la anterior, y dos construcciones anexas de pequeñas dimensiones unidas a las anteriores a través de los corrales.

$\mathrm{Su}$ estado es bastante penoso, encontrándose su interior en una verdadera ruina. Los muros exteriores tienen des- plomes, existiendo grietas en las zonas cercanas a las esquinas debidas a empujes de la cubierta. Esta se encuentra en malas condiciones debido a que la penetración de agua ha ido pudriendo las cabezas de los parecillos en su unión con los muros y a que el entablado está muy deteriorado. En cuanto a su estructura formada por vigas y pilares de madera de roble, tiene problemas de aplastamiento en las uniones de vigas y pilares, asi como grandes desplomes de casi todos los pilares. Los forjados y la tabiquería o no existen ya o se encuentran en muy mal estado.

\section{Nuevo uso}

Por todo lo expuesto anteriormente se propone formar, con este conjunto de casas, una unidad de vivienda-aula con capacidad para catorce alumnos y dos profesores, distribuyéndose de la siguiente forma:

- La primera casa, que dispone de dos alturas, se destina a vivienda de alumnos. En planta baja se dispone
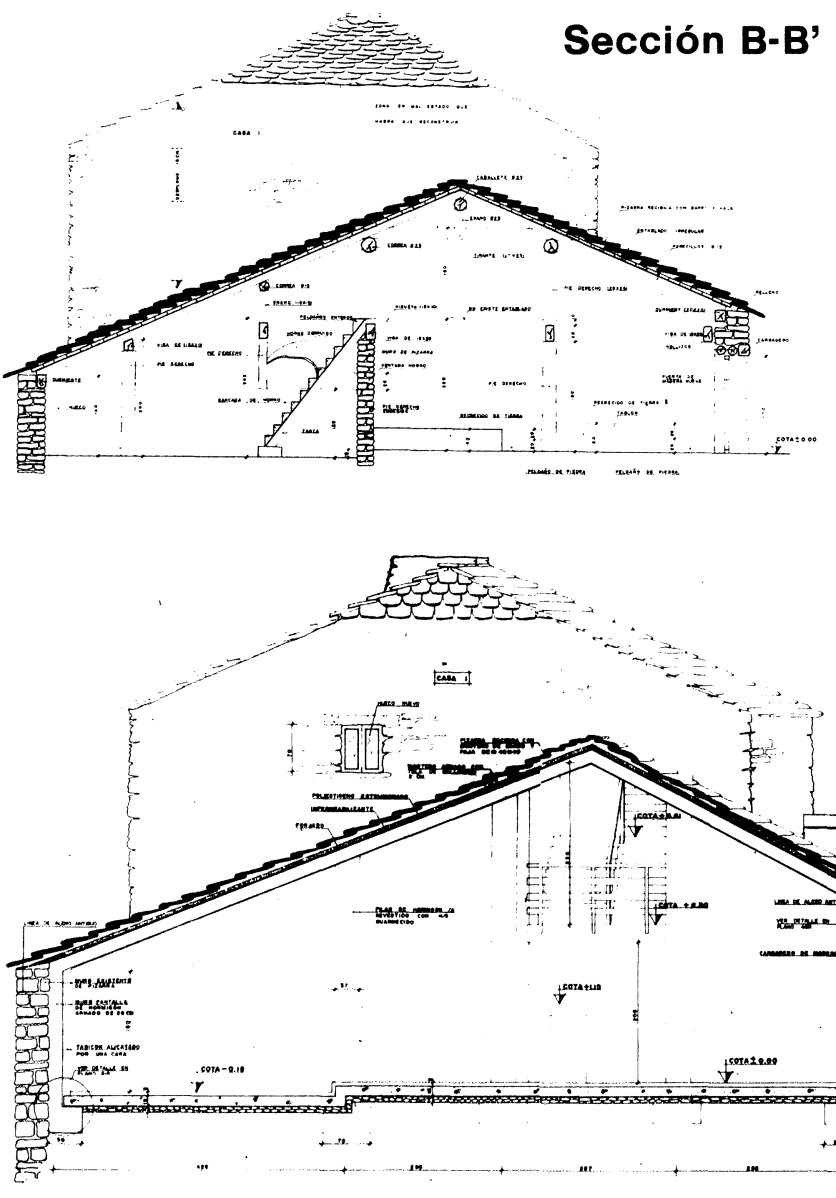

el vestíbulo, zona de estar y cocina. La zona de estar está dividida por agrupaciones de bancos realizados en albañilería, creando asi cuatro zonas diferenciadas. En esta zona de estar existe una entrada a un horno exterior que habrá que reconstruir por estar medio hundido, así como una estufa de leña que sea fuente de calor suficiente para calentar la estancia. La cocina no está pensada para dar servicio permanente a todo el alumnado, pues ya existe en el pueblo un comedor para ese uso, sino solamente para realizar pequeñas comidas ocasionales. En el vestíbulo arranca una escalera que comunica, por un lado con la casa de al lado y por otro con la planta alta en la que está ubicada la zona de dormitorios con capacidad para catorce alumnos y los servicios.

\section{Distribución}

Planta alta

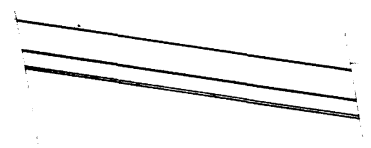
(reformada)
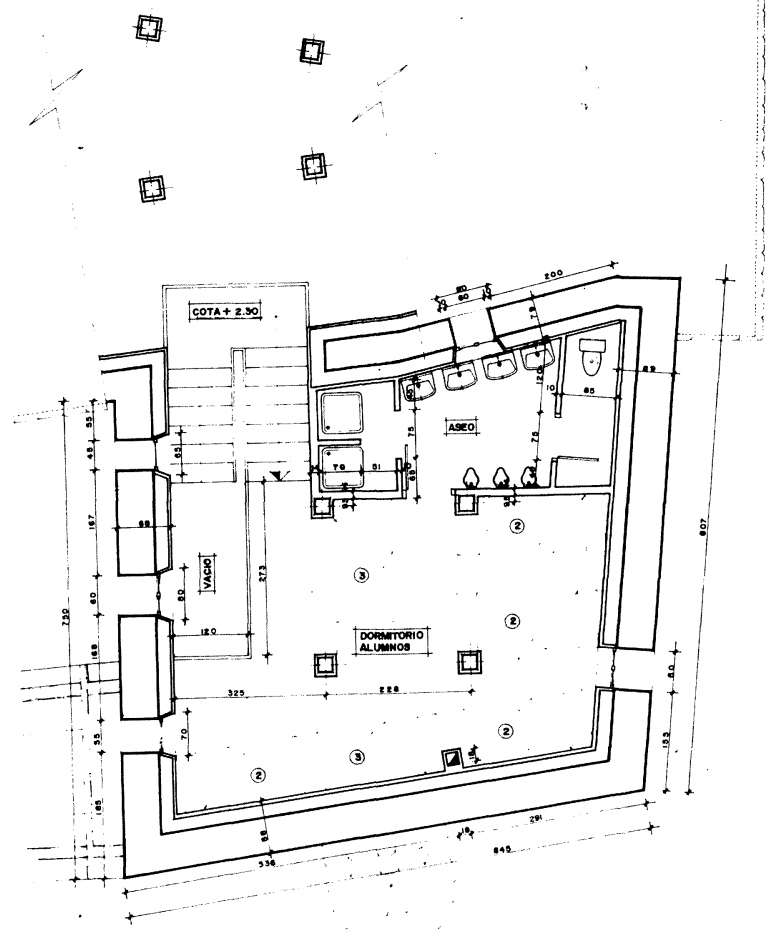

Sección B-B' 
- La segunda casa, que es de una altura, se acondiciona para aula de trabajo y laboratorio. El aula está situada en fachada y el laboratorio al fondo.

- La tercera construcción, que es una tinada y que se encuentra separada unos metros de las anteriores, se destina para vivienda de profesorado. Consta de vestíbulo, dormitorio para dos camas y cuarto de baño.

- Además de estas tres construcciones, se dotará al conjunto de un merendero de verano y de una leñera situados en la fachada principal y formados con el aprovechamiento de los muros exteriores existentes.

\section{Solución constructiva}

Teniendo en cuenta el estado constructivo actual y el programa de necesidades, se actúa teniendo en cuenta las siguientes premisas:

- Realizar una intervención integrada con el resto de la arquitectura del pueblo, conservando el cascarón exterior del edificio.

- Al estar el edificio interiormente en estado de ruina, se vacía éste y se construye de nuevo todo el interior con una nueva distribución y tecnologias actuales. Pudiendo decir que se realiza una casa dentro de otra.

- Debido al nuevo programa de necesidades se necesita acondicionar el interior de las viviendas, dotándolas de instalaciones adecuadas y resolviendo una serie de problemas causados por las pequeñas alturas existentes y por'la escasez de huecos de ventanas. Por ello se elimina la planta de sobrado para poder dar alturas interiores adecuadas a los diferentes niveles y se abre algún nuevo hueco en fachada pero respetando su composición y proporción.

- Necesidad de consolidar los muros exteriores de fachada sin variar su aspecto exterior.

Para comenzar las obras, el primer trabajo a realizar será el desmontaje de todos los elementos que componen el interior del edificio (tabiquería, forjados, carpinteria, etc.) dejando la estructura principal como arriostramiento de los muros. A continuación se desmonta la cubierta, al mismo tiempo que se consolidan los muros, teniendo especial cuidado con las lajas de pizarra que habrá que volver a utilizar, abriendo los nuevos huecos de fachada. Hemos de procurar tener poco tiempo el edificio sin cubierta y realizar cuanto antes la cimentación y muros perimetrales de hormigón armado, que además de ser parte de la nueva estructura, son elementos de consolidación y sujeción de los muros existentes a modo de pantallas. La parte inferior de estos muros son de hormigón hidrófugo para evitar humedades de capilaridad.

La estructura está compuesta además por pilares y vigas "ratas» de hormigón armado, con forjados unidireccionales aligerados con bovedillas cerámicas. Los muros van trasdosados por tabique de ladrillo y cámara con aislante, pues a pesar del grosor de estos muros el edificio no cumple con la $\mathrm{K}_{\mathrm{a}}$ exigida por la norma. Asimismo se coloca aislante en la cubierta además de la impermeabilización, y cubriendo con lajas de pizarra recuperadas del derribo. Los trasdosados de las pantallas de hormigón permiten realizar rozas para el alojamiento de las conducciones.

En la vivienda de profesores no es necesario consolidar los muros de cerramiento, pues se encuentran en buen estado. Unicamente se sustituirá su cubierta y se tomarán las medidas necesarias para evitar humedades. 


\section{DOS CASAS DESTINADAS A VIVIENDA-AULA (ZONA SUR)}

Cecilio Almendros Cuenca, Eloy Frondroso Sánchez, L. Carlos Izquierdo Gracia, Juan A. Jerónimo de Paz y Eulalio Morejudo Martínez

\section{Descripción del edificio en su estado actual}

La intervención se desarrolla en la parte sur de la citada manzana de intervención. El conjunto está formado, al igual que en la parte norte, de dos viviendas adosadas una de dos plantas con tinada adosada y otra de una sola planta. Además existe un horno exterior adosado a una de las viviendas conservándose bastante bien.

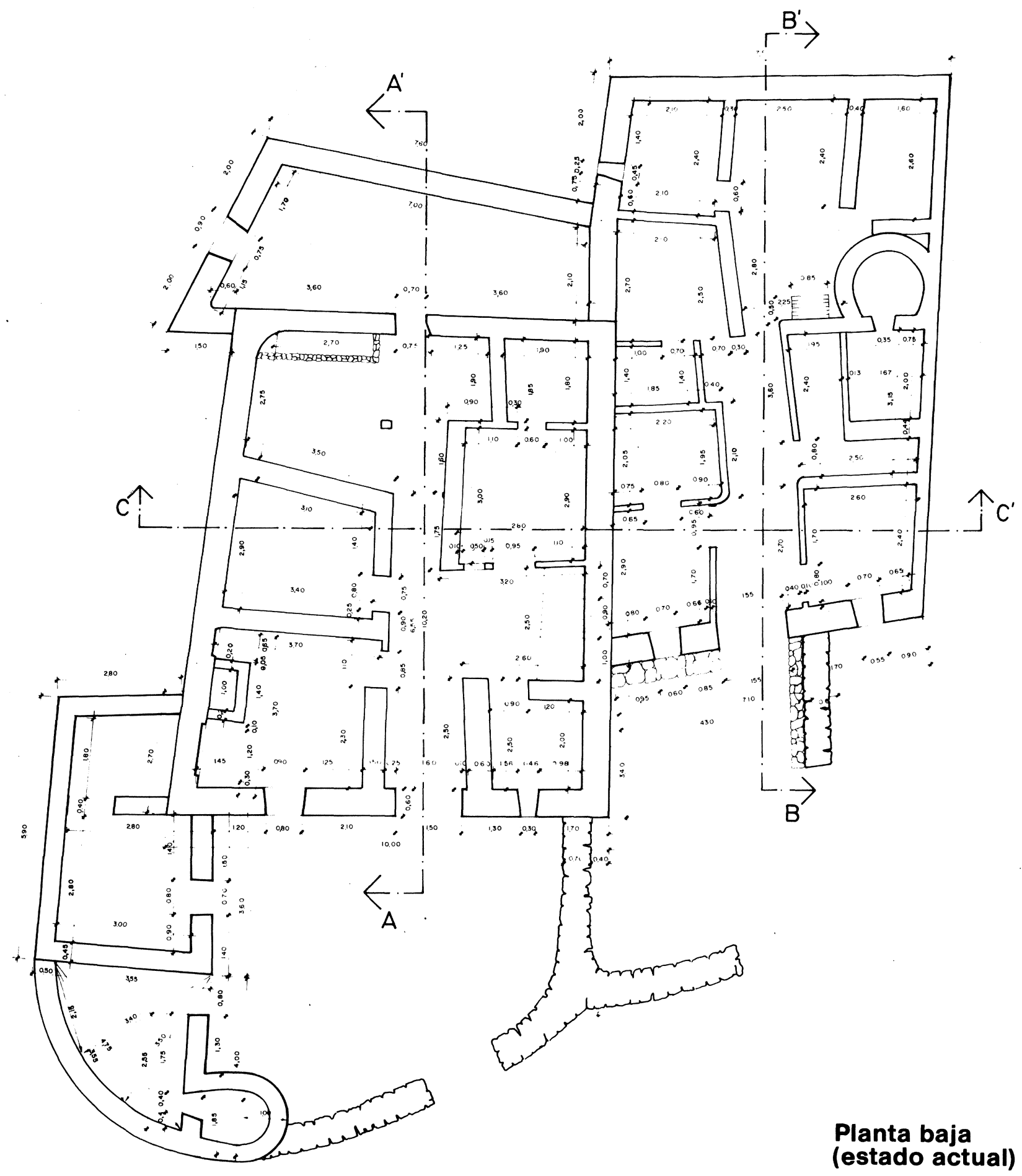


La construcción se encuentra en un estado similar al descrito para el resto de la manzana. En algunas partes de la cubierta la pizarra ha sido sustituida por teja curva como material de cubrimiento, ya que al no encontrarse personal cualificado para la formación de estas cubiertas de pizarra, la teja ofrecía mayores garantías de éxito.

\section{Nuevo uso}

El programa de necesidades es el mismo que para la an-

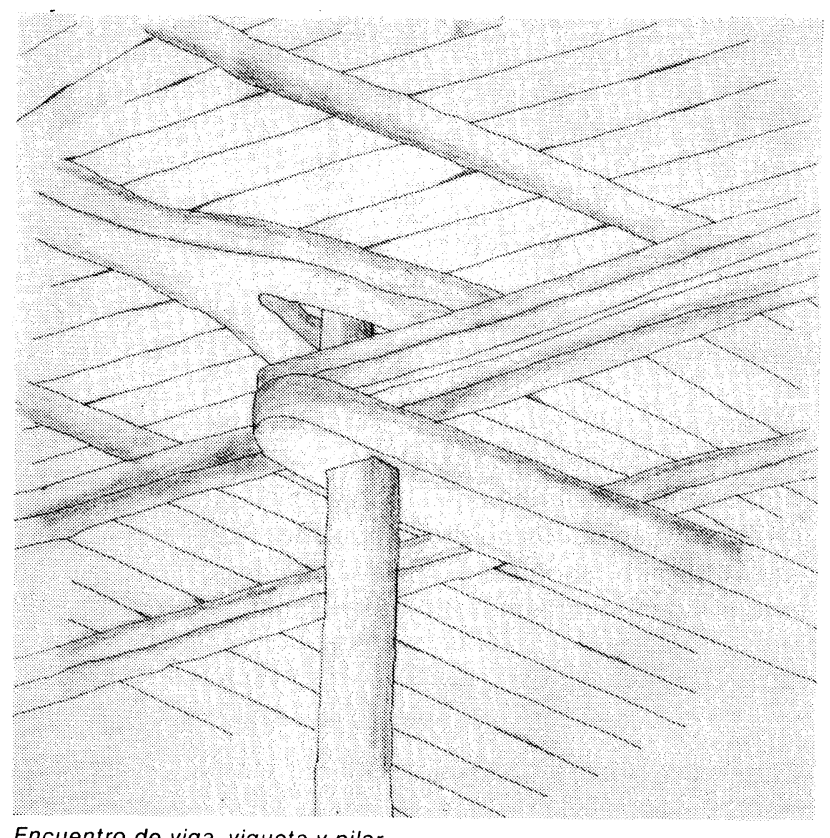

Encuentro de viga, vigueta y pilar.

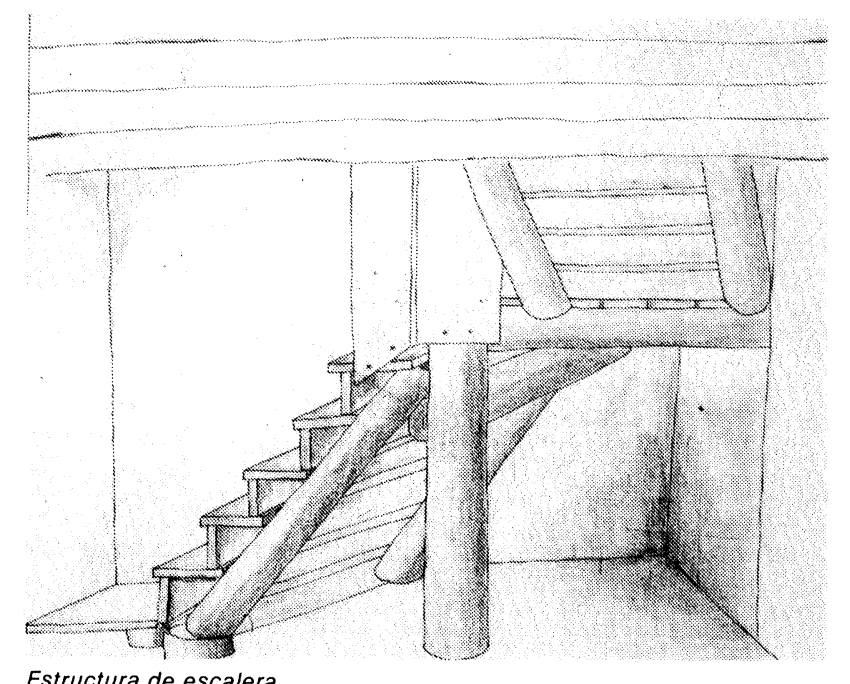

Estructura de escalera. terior intervención, distribuyéndose los espacios de forma parecida:

- La casa de dos plantas se destina a alojamiento, con dormitorios ( 18 alumnos) y servicios en planta alta y zona de estar y cocina en planta baja, comunicadas por una escalera que al mismo tiempo sirve de enlace a través de los rellanos con la segunda casa por existir una diferencia de nivel de media altura. La tinada adosada a la parte posterior de la casa se utiliza para dormitorio de profesores.

- En la casa de una planta se desarrolla la zona de trabajo utilizando la planta baja para laboratorio, despacho y exposición de trabajos, y la entreplanta (situada en la parte central con mayor altura de cubierta) para aula.

- Por último se acondiciona toda la parte exterior de fachada principal para su utilización en verano.

\section{Solución constructiva}

En la solución arquitectónica se ha partido de las mismas premisas fijadas que para el resto del conjunto, aunque algunas soluciones constructivas concretas varían, siendo la estructura en este caso mixta con pantalla perimetral de hormigón armado y estructura interior de madera de similar diseño a la existente.

La obra se inicia por la casa de una planta puesto que está más sujeta al estar entre medianerías y ser la otra de mayor altura y en posición de cabeza.

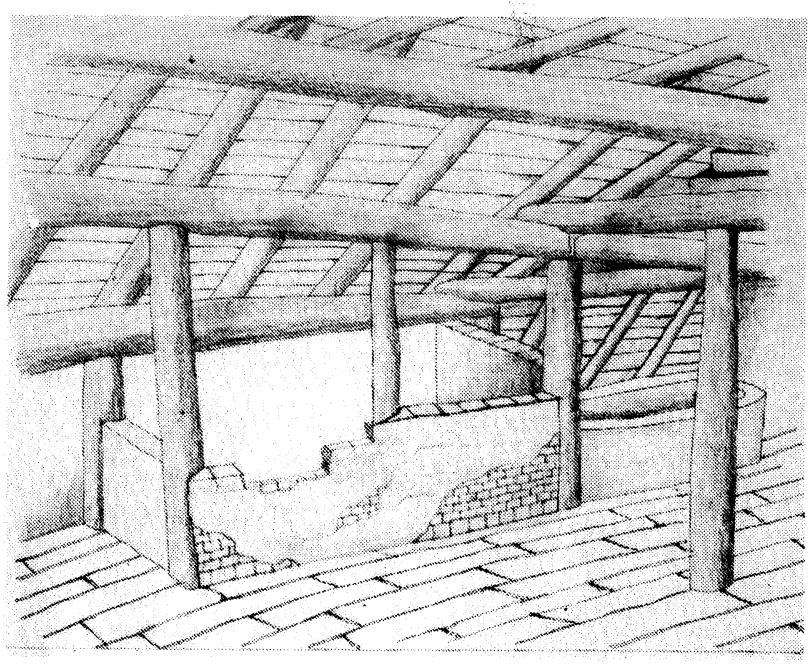

Entramado de cubierta y sobrado. 


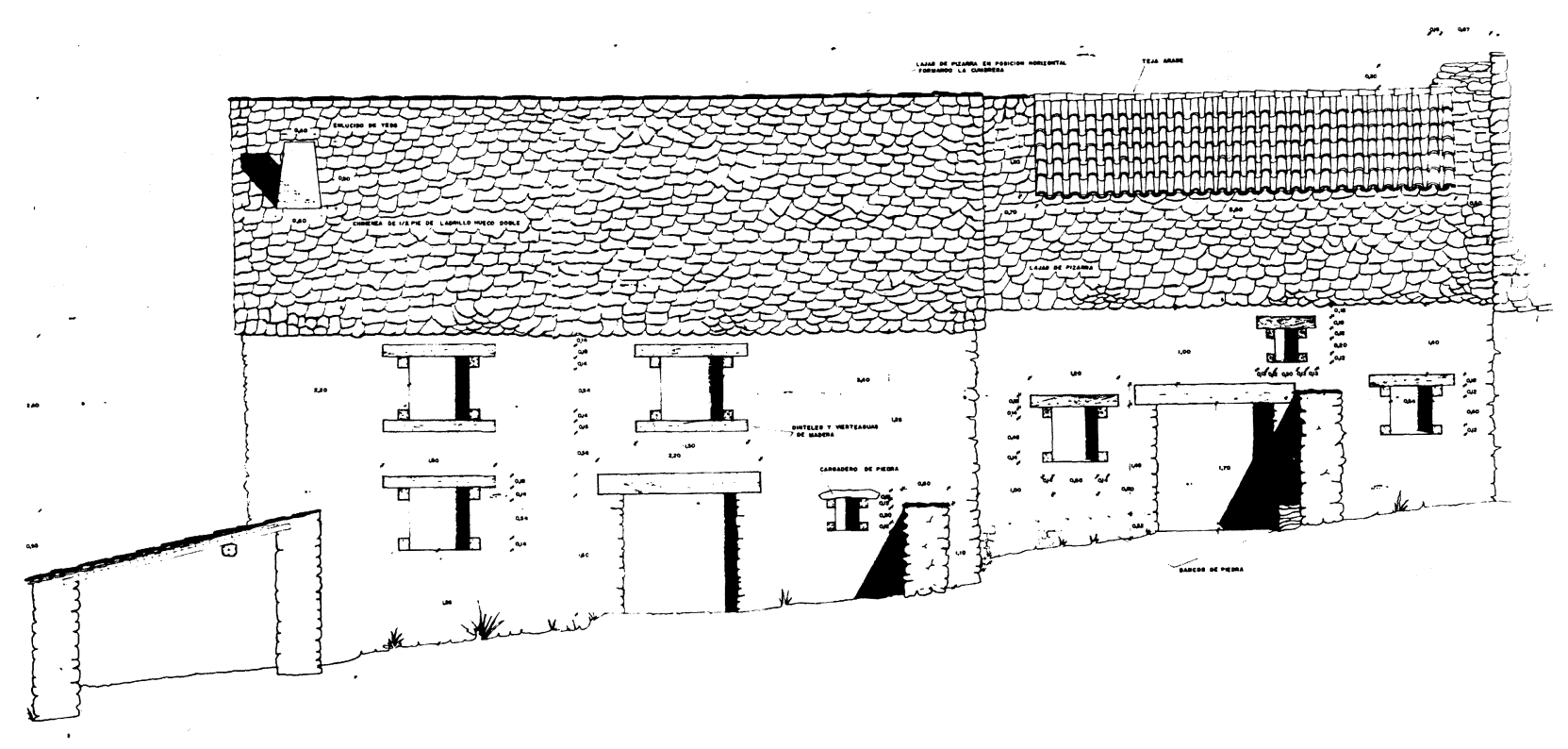

Alzado sur (estado actual)

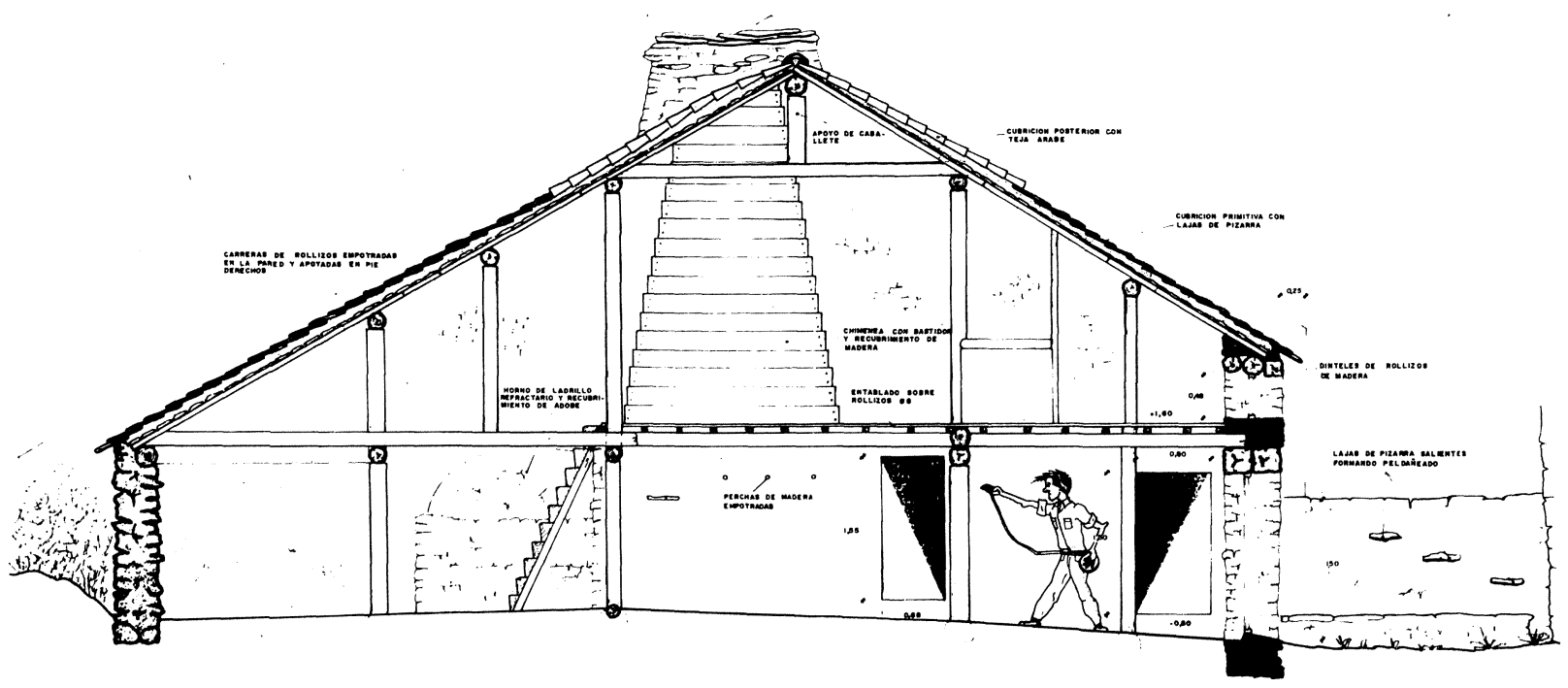

\section{Sección B-B' (estado actual)}




\section{Fases de derribo}

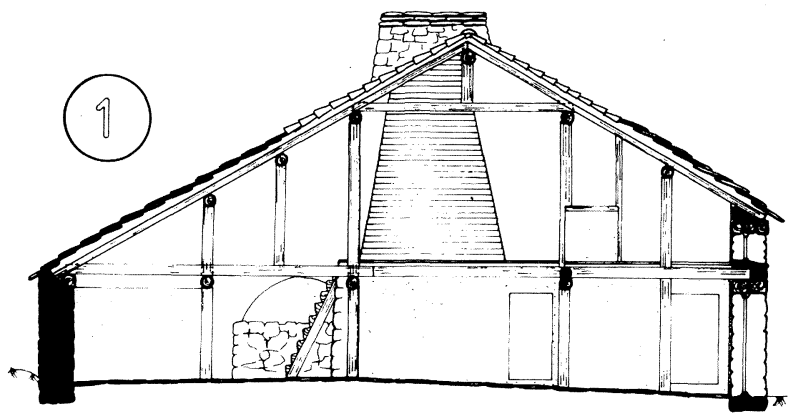

Estado sección actual.

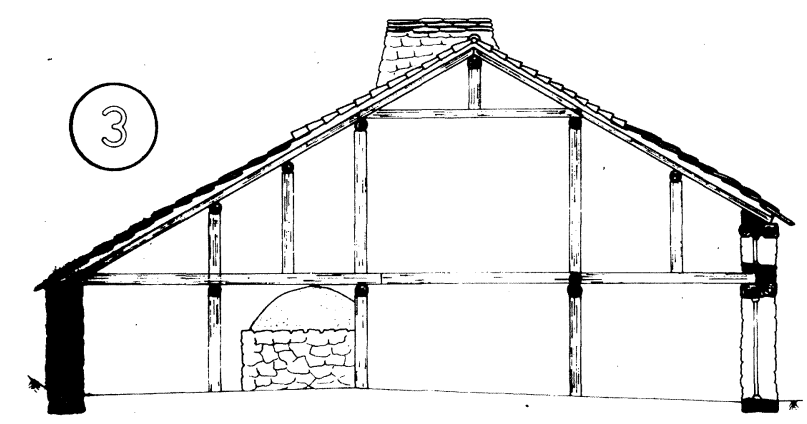

Desmontaje de suelos, escaleras y chimeneas.

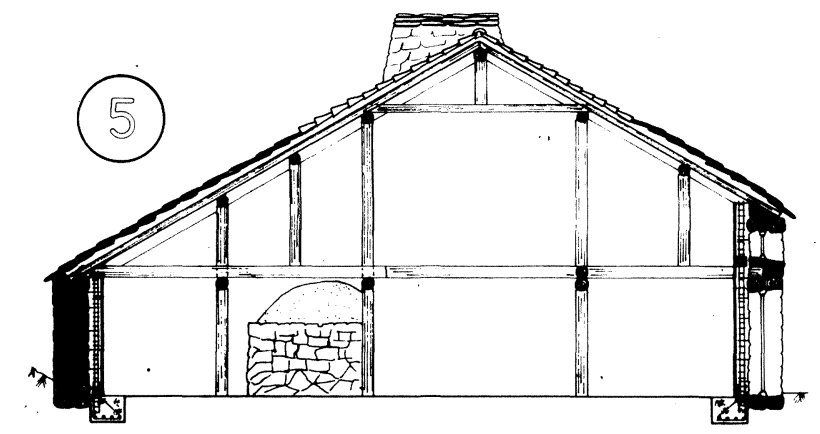

Encofrado de ladrillo hueco, colocación de armaduras y hormigonado.

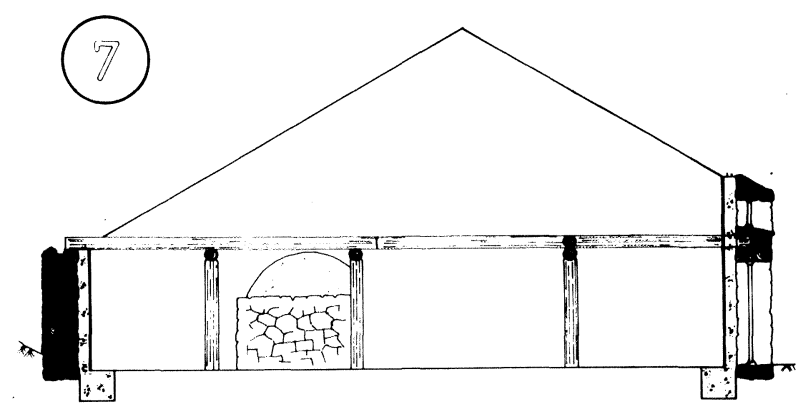

Desmontaje de estructura en planta primera.

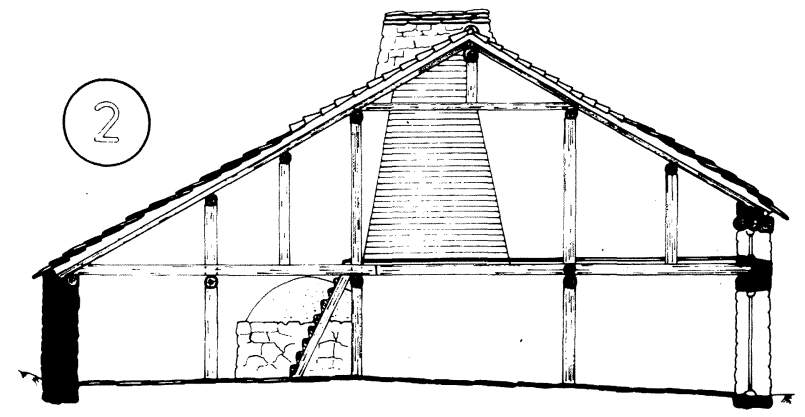

Desmontaje: mobiliario, escombros, puertas, tabiques, enfoscado de yeso y barro.

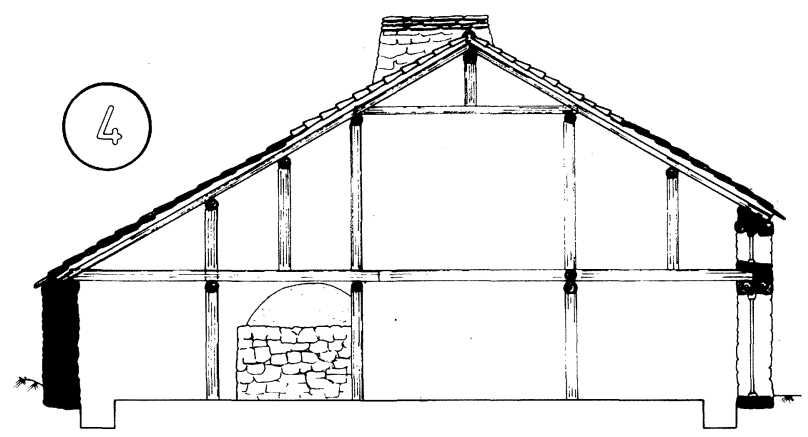

Explanación de suelo y apertura de zanjas.

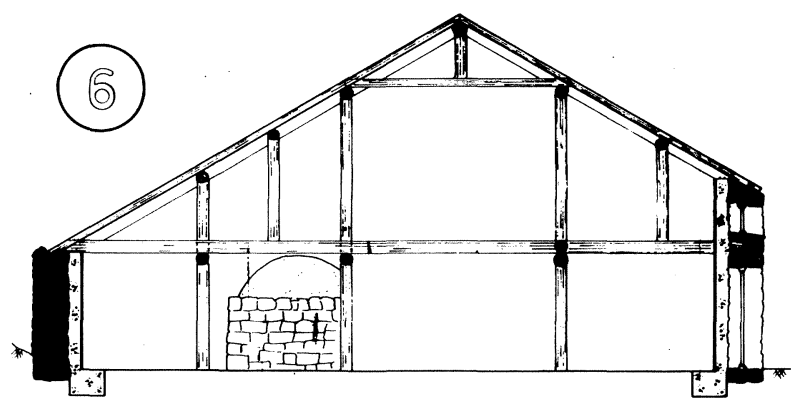

Desmontaje de cubierta.

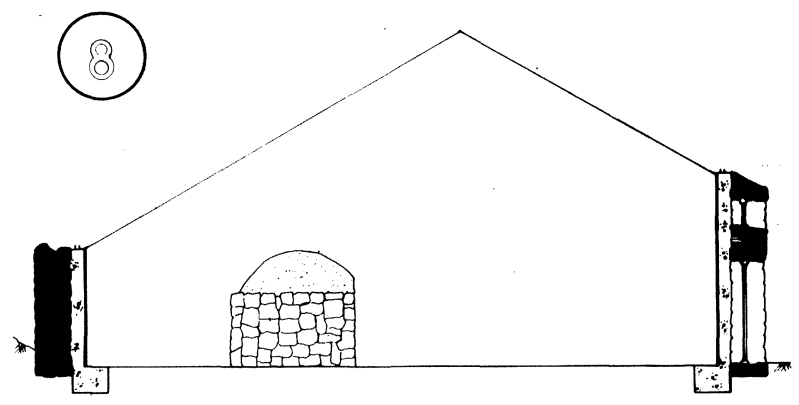

Desmontaje de estructura en planta baja. 


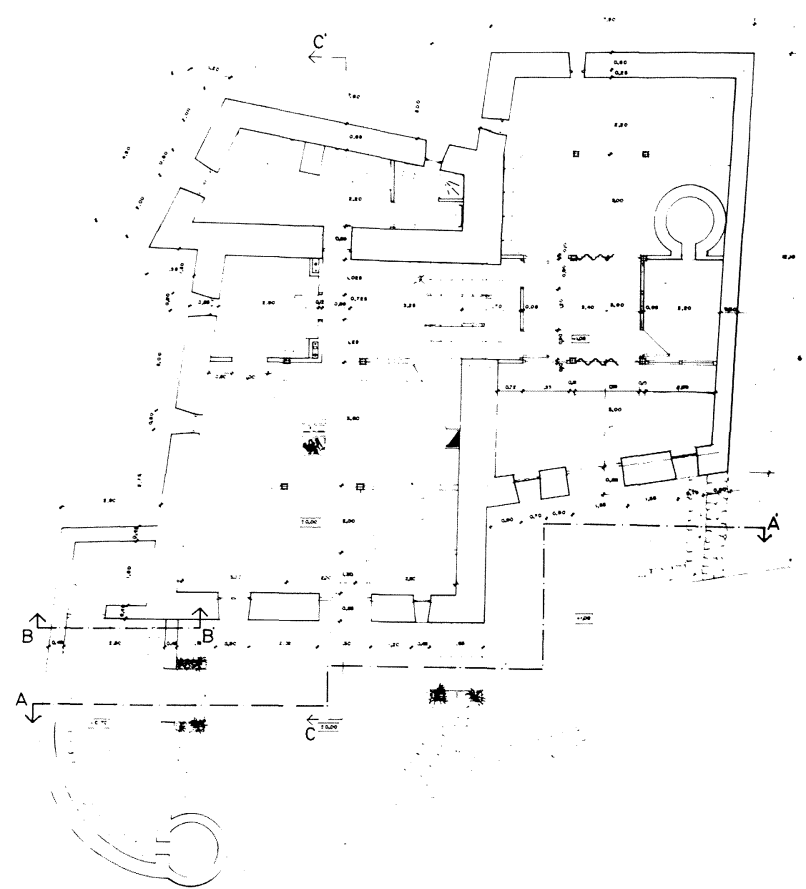

Planta baja (reformada)

El proceso de construcción es el siguiente:

- Retirada de tabiques, acabados (suelos y revestimiento), escalera, carpinteria interior, forjados.

- Excavación de las zanjas de cimentación corrida para las pantallas perimetrales y del cajeado necesario hasta la profundidad que el suelo lo permita (por ser rocosa) para la formación de la solera, perdiendo la minima altura interior posible.

- Construcción de la pantalla perimetral de hormigón armado mediante un encofrado perdido formado por tabique de ladrillo hueco y que cumplirá la función de

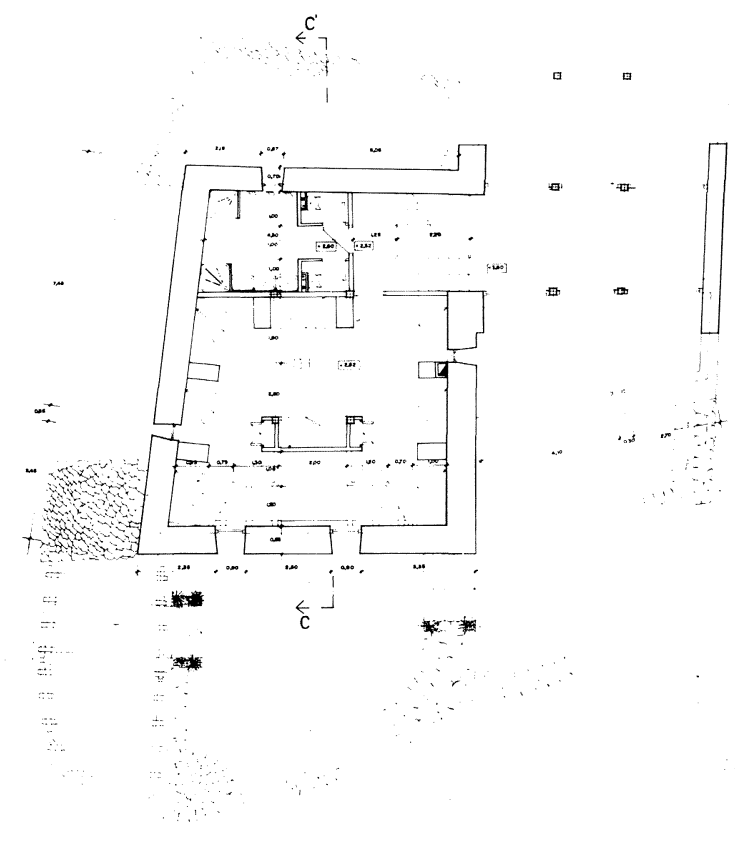

Planta primera (reformada)

sujeción de las fachadas y de apoyo de la estructura interior de madera mediante apoyos estudiados al efecto.

- Desmontado de la cubierta cuando la pantalla ha obtenido la altura suficiente para mantener el conjunto en pie.

- Montaje de la estructura interior incluidos los forjados y escaleras.

- Formación de la cubierta nueva y las obras interiores necesarias. 